\title{
Double outlet from chambers of left ventricular morphology
}

\author{
EDUARDO OTERO COTO ${ }^{1}$, MANUEL QUERO JIMENEZ, ALDO R. CASTANEDA, \\ JUAN J. RUFILANCHAS, AND PHILLIP B. DEVERALL
}

\author{
From Centro Especial 'Ramon y Cajal' and Clinica 'Puerta de Hierro' Madrid, Spain; Children's Hospital \\ Medical Center, Boston, USA; and Killingbeck Hospital, Leeds
}

SUMMARY This series of 5 cases with double outlet of morphologically left ventricular chamber includes 4 found during a review of 1700 heart specimens (incidence $0.23 \%$ ) and 1 found at operation and successfully corrected. Abnormal atrioventricular connection precluding total correction was present in the 4 anatomical cases. Clinical diagnosis may be difficult and it is suggested that axial cineangiography may make anatomical diagnosis easier. Absence of the infundibular septum and aortic laevoposition are frequent. As some cases can be surgically corrected, accurate information is required on the size of the right ventricle, the morphology and function of the atrioventricular valves, the presence, size, and position of the ventricular septal defect, and the degree and type of outflow tract obstruction.

In double outlet left ventricle (DOLV), both great arteries are connected to the left ventricle. If a ventricular septal defect underlies only one of the great arteries, DOLV exists when more than one and a half great arteries arise from the left ventricle (Kirklin, 1973). However, when a doubly committed type of ventricular septal defect is present such a definition should be modified in the sense that more than half of each great artery has to arise directly from the left ventricle (Otero Coto and Quero Jimenez, 1977). Occasionally, the presence of an exactly biventricular origin of a great artery will make its assignment to either ventricle impossible (Brandt et al., 1976).

This anomaly was first reported by Marechal in 1819 (Van Praagh and Weinberg, 1977), and mentioned as a possibility by Rokitansky in 1852 . We have found no other published case until 1962 when Fragoyannis and Kardalinos described as DOLV a heart which eventually was shown to have a double outlet 'right' ventricle with atrioventricular discordance and situs solitus. Subsequently DOLV was regarded as an 'embryological impossibility' (Anderson et al., 1974). In 1967 Sakakibara et al. reported the first successful repair of a DOLV; surgical experience was further amplified by Pacifico et al. (1973). Interest in this entity was further increased by the report by Paul et al. (1970) of the

${ }^{1}$ Dr Otero-Coto is an Evarts A. Graham Memorial Travelling Fellow of the American Association for Thoracic Surgery.

Received for publication 17 July 1978 first anatomically proven case of DOLV with intact interventricular septum.

Since approximately 75 per cent of all cases of DOLV hitherto reported (Van Praagh and Weinberg, 1977) seem amenable to surgical correction, continued interest in this relatively uncommon lesion is justified.

\section{Subjects}

Of the 5 cases of double outlet from a morphologically left ventricular chamber presented in this paper, 4 were identified during a review of 1700 heart specimens with congenital heart malformations $(0 \cdot 23 \%)$. Case 5 was diagnosed in the operating room and treated surgically.

\section{CASE $1^{1}$ : VISCERO-ATRIAL SITUS SOLITUS WITH LEFT-SIDED CARDIAC APEX}

The right atrium received the coronary sinus and venae cavae, and showed tricuspid atresia with a dimple situated above the main (morphologically left ventricular) chamber. A patent foramen ovale was present. The left atrium received the pulmonary veins and connected with the ventricle through an abnormal atrioventricular valve possessing two leaflets and a large deficiency in the anterior commissure, the commissural tissue being attached by very short chordae tendineae to the ventricular wall. The great arteries arose side by side from this

${ }^{1}$ Previously reported by Quero Jimenez and Maitre Azcárate (1975). 
morphologically left ventricle, with the aorta to the right of the pulmonary artery. A bilateral infundibulum prevented fibrous continuity between semilunar and atrioventricular valves. Laevoposition of the infundibular septum resulted in a malalignment type of ventricular septal defect, limited by the superior border of the muscular interventricular septum and the subaortic free wall. Both semilunar valves were morphologically normal, the pulmonary valve being dilated. The ventricular septal defect communicated with a small cavity, with right ventricular morphology but without valve apparatus or direct connection with any other chamber or vessel. A single coronary artery orifice was present and no delimitant coronary arteries were found. The aortic arch was left-sided and a large persistent ductus arteriosus was present.

\section{CASE $2^{1}$ : SITUS AMBIGUUS WITH ASPLENIA}

AND RIGHT-SIDED CARDIAC APEX

No interatrial septum was present except for a small anterosuperior remnant (single atrium). There was only one atrioventricular valve of primitive morphology with 4 leaflets opening into a morphologically left ventricular cavity. In the right posterior part of this ventricle a small recess was present, perhaps corresponding to the remnant of the apical recess. Both great arteries arose from the ventricle, being supported by a bilaterally developed infundibulum. The aorta was situated in front and to the left of the pulmonary artery. The aortic arch was right-sided. Mild valvar and subvalvar pulmonary stenosis was present. No coronary sinus was found.

CASE 3: VISCERO-ATRIAL SITUS SOLITUS

WITH LEFT-SIDED CARDIAC APEX

A patent, dilated, foramen ovale was present. The atria were morphologically normal and drained through atrioventricular valves of similar size and morphology (each having two leaflets) into a single morphologically left ventricle (Fig. 1). The pulmonary artery and most of the aorta arose from this chamber. There was fibrous continuity between the pulmonary valve and the right atrioventricular valve, but the aortic valve was supported by a welldeveloped subaortic infundibulum. The small infundibular septum was laevoposed and situated on the roof of the ventricle (Fig. 2); its anterior prolongation formed an abnormal band to the left of the muscular septum. A large ventricular septal defect $(3 \times 2 \mathrm{~cm})$, limited by the superior border of the muscular septum, the subaortic infundibular free wall, and the anterior ventricular wall, com-

${ }^{1}$ Also included in a series of anomalien with aortic laevoposition (Otero Coto et al., 1978).

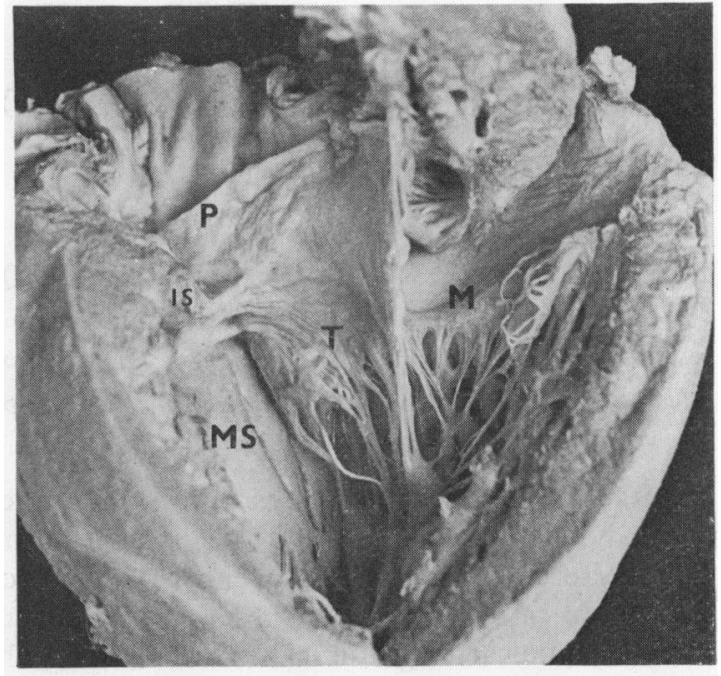

Fig. 1 Case 3. Inflow tract showing both atrioventricular valves, of similar morphology, draining into the morphologically left ventricular main chamber. The pulmonary valve $(P)$ is in fibrous continuity with the right atrioventricular valve $(T)$. M, left atrioventricular valve; $I S$, infundibular septum; MS, muscular septum.

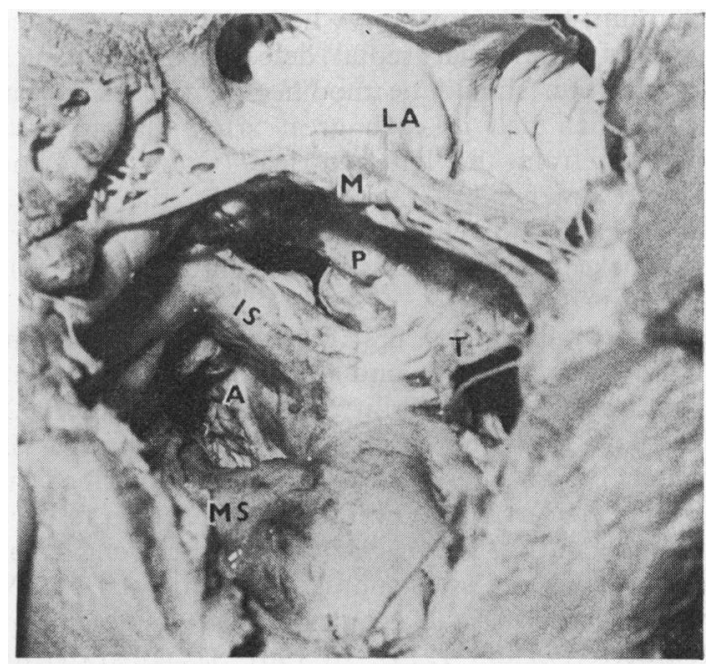

Fig. 2 Case 3. Outflow tract showing both great arteries connected with the morphologically left ventricular main chamber and separated by the infundibular septum (IS), which is clearly malaligned with the muscular septum (MS). The right atrioventricular valve $(T)$ is shown in fibrous continuity with the pulmonary valve $(P)$ and the left atrioventricular valve $(M)$ has been opened with the left atrium $(L A)$, through an incision in the left lateral border of the heart. 


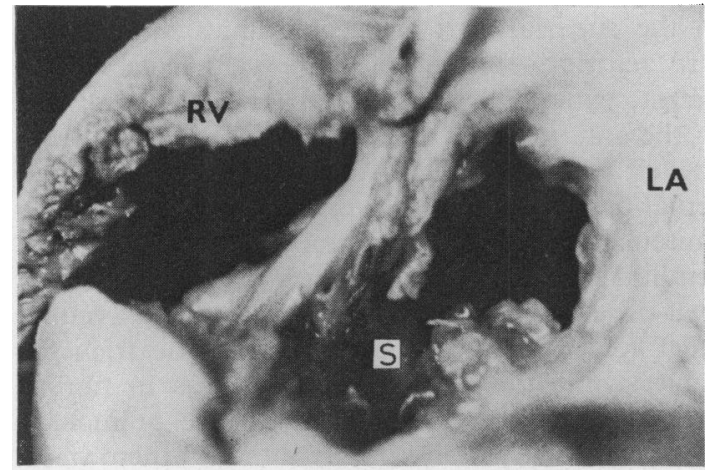

Fig. 3 Case 4. The straddling left atrioventricular valve is seen with its major part, showing dysplastic changes, entering the left (right-sided) ventricle. LA, left atrium; $R V$, right (left-sided) ventricle; $S$, interventricular septum.

municated with a chamber in which there were no remnants of valve apparatus; this small chamber showed a right ventricular pattern of trabeculation. Both semilunar valves were normal, the aortic valve being anterior to and to the left of the pulmonary valve. Two coronary arteries were present; the right coronary artery crossed the pulmonary outflow tract and its peripheral pattern was bizarre. The aortic arch was left-sided.

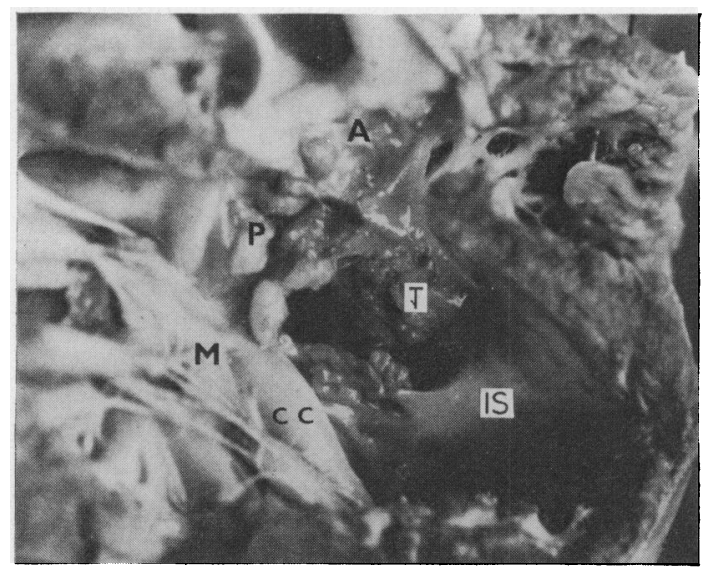

Fig. 4 Case 4. The morphologically left (right-sided) ventricle has been opened, showing the origin of both great arteries. The left (right-sided) atrioventricular valve (M) is morphologically abnormal, with 6 well-developed papillary muscles. $A$ well-developed posterior muscular column (CC) is placed between the atrioventricular valves. The right (left-sided) atrioventricular valve $(T)$ straddles the posterior part of a ventricular septal defect. The semilunar valves are in fibrous continuity as a result of the absence of the infundibular septum. The pulmonary valve is seen in fibrous continuity with both atrioventricular valves. $A$, aorta; $P$, pulmonary valve; $I S$, interventricular septum.
CASE 4: ATRIAL SITUS SOLITUS AND

LEFT-SIDED CARDIAC APEX

The right atrium, morphologically normal, showed a patent foramen ovale and was connected through a bizarre atrioventricular valve, with 6 welldeveloped papillary muscles, to a right-sided morphologically left ventricle. The left atrium, morphologically normal, communicated with both ventricular cavities through a straddling left-sided atrioventricular valve, which showed dysplastic changes where it communicated with the left ventricle (without chordae tendineae or papillary muscles) and normal morphology on its right (left-sided) ventricular aspect (Fig. 3). In the left ventricle there was a well-developed posterior muscular column between the atrioventricular valves. Both great arteries arose above the left ventricle; no infundibular septum was present and the aortic valve, directly anterior to the pulmonary valve, was partially related to the right ventricle (Fig. 4). The large ventricular septal defect was limited by the muscular interventricular septum, the right atrioventricular valve, the aortic valve and subaortic infundibular free wall, and the anterior ventricular wall. There were 2 coronary arteries with the usual pattern for corrected transposition. The aortic arch was left-sided.

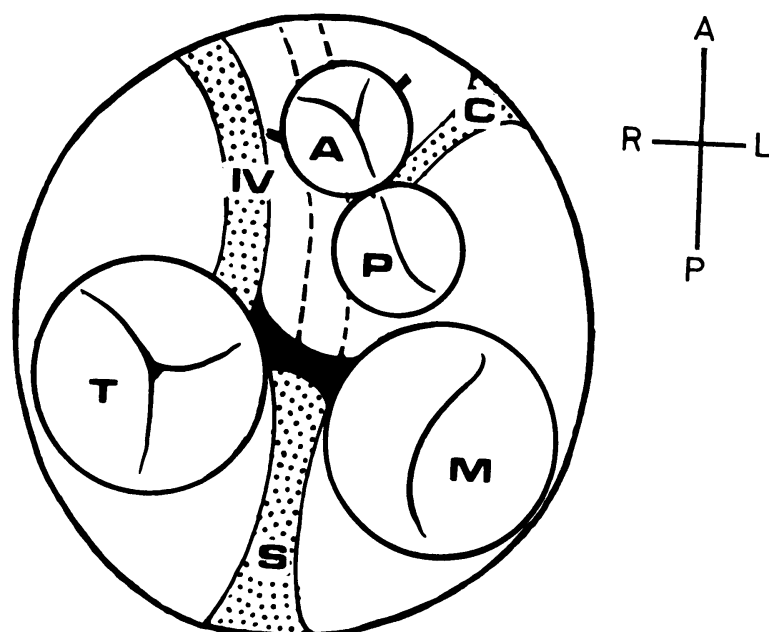

Fig. 5 Schematic drawing of the relations between valves and septa in case 5, looking towards the base of the ventricles. The position of the muscular interventricular septum in the anterior part is depicted by the dashed lines. $T$, tricuspid valve; $M$, mitral valve; $A$, aortic valve; $P$, pulmonary valve; $S$, sinus or inlet septum; IV, infundibulo-ventricular fold; $C$, infundibular free wall. 
CASE 5: ATRIAL SITUS SOLITUS

The right atrium received 2 venae cavae and the coronary sinus, and communicated through a large ostium secundum atrial septal defect with a morphologically normal left atrium receiving 4 pulmonary veins. Morphologically normal atrioventricular valves established a concordant atrioventricular connection. The right ventricle, of normal size, showed a large abnormal muscle bundle

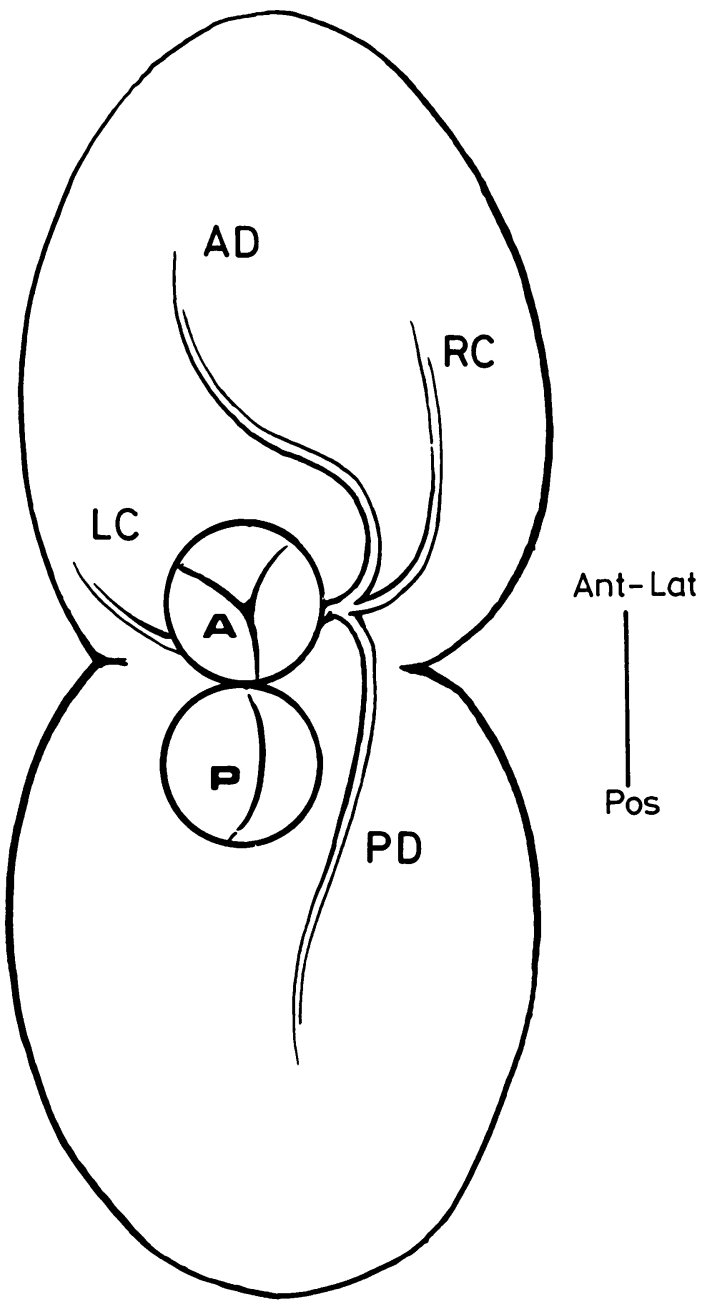

Fig. 6 Schematic representation of the course and distribution of the main coronary arteries in case 5. An imaginary cut perpendicular to the plane of the interventricular septum separates the anterolateral from the posterior or diaphragmatic aspects of the heart. $R C$, right coronary artery; $L C$, left circumflex; $A D$, anterior descending; $P D$, posterior descending; $A$, aorta; $P$, pulmonary artery. in the superior part and communicated with the left ventricle through a large ventricular septal defect, extending from the atrioventricular valves to the anterior wall. Both great arteries arose from the left ventricle and were related to the ventricular septal defect (doubly-committed type) (Fig. 5). No muscular infundibular septum was present, the semilunar valves being in fibrous continuity. A well-developed conal free wall (infundibulo-ventricular fold) separated the aorta from the tricuspid valve, while the pulmonary valve was in fibrous continuity with the mitral valve. The pulmonary valve was bicuspid and mildly stenotic; there was a fibrous shelf below the pulmonary valve, producing moderate obstruction. Both anterior and posterior descending coronary arteries arose from the right coronary artery (Fig. 6) There was no innominate artery, the right subclavian and common carotid arteries arising independently from the left-sided aortic arch.

Surgical correction was achieved by closing the ventricular septal defect, thus leaving both great arteries connected to the left ventricle, and placing an external valved conduit (Hancock no. 18) between the right ventricle and the pulmonary artery. The pulmonary valve was closed by direct suture. In addition a large atrial septal defect was closed with a patch. The postoperative course was uneventful. Fig. 7 illustrates the view through the tricuspid valve of the ventricular septal defect and the origin of both great arteries. Fig. 8 shows the steps taken in the correction of the malformation.

\section{Discussion}

These cases further illustrate the large number of anatomical variations that can occur with double outlet of morphologically left ventricular chamber. The main reported variations relate to the presence or absence and location of the ventricular septal defect or pulmonary stenosis, the infundibular muscular distribution, and the relations of the great arteries. Anomalies of the atrioventricular valves, of the atrioventricular connections, and of the right ventricle or its equivalent are also frequent. Each of the 5 cases presented here had a different type of atrioventricular connection; 2 had a single atrioventricular valve, one with typical mitral morphology, except for the presence of a large deficiency in the anterior commissure, and the other with primitive morphology (this being the only reported case with asplenia to our knowledge). The other 3 cases had 2 atrioventricular valves, but in one both valves opened into the morphologically left ventricle, in another the right (left-sided) atrioventricular valve was straddling the interventricular septum in 


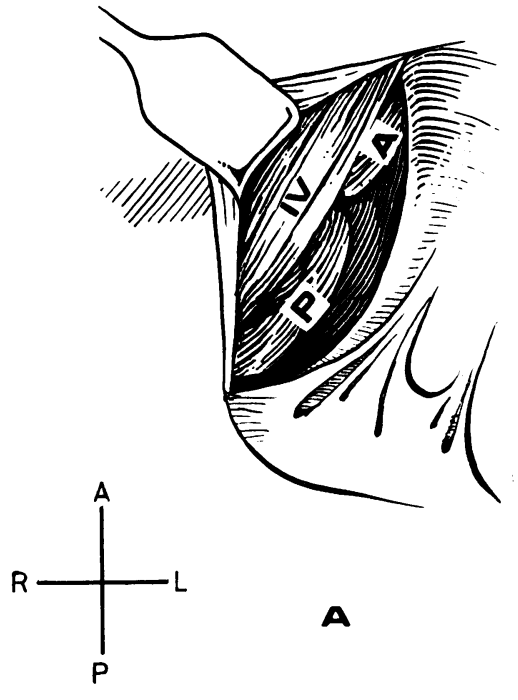

a case with discordant atrioventricular connection, and in the third case, surgically corrected, both atrioventricular valves connected normally with the appropriate ventricles.

None of the 5 cases was accurately diagnosed before death or operation. The lesion is a rare one

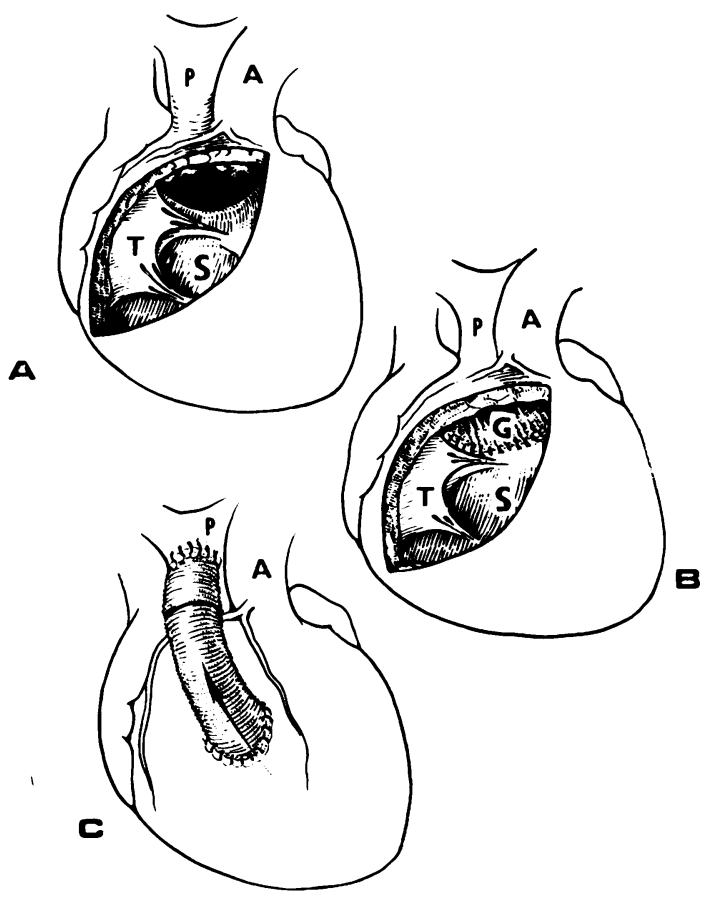

and often therefore unsuspected, and angiocardiographic interpretation can be difficult. Selective left ventriculography has been considered (Pacifico et $\mathrm{cl}$., 1973) the best way of demonstrating the preserce of DOLV, but right ventriculography can also be of value in some cases (Brandt et al., 1976). In our view, a number of projections, including those selective for the anterior part of the interventricular septum (hepatoclavicular technique and long axis oblique view of Bargeron et al., 1977), may bc necessary, particularly in cases of transposition of the great arteries with subaortic ventricular septal defect (Quero Jimenez and Perez Martinez, 1974) or anatomically corrected malposition (Otero Coto, 1977).

Perhaps the greatest difficulty in the diagnosis of DOLV lies in accurately applying the 50 per cent rule. Cases with absence of the infundibular septum are particularly difficult to classify. With normally related great arteries the outflow tracts cross and a large deficiency of the septum below one or both

Fig. 8 Diagrams illustrating the steps followed in the correction. (A) Right ventriculotomy allowed good exposure of the origin of both great arteries to the left of the interventricular septum. (B) After closure of the ventricular septal defect both great arteries connected to the left ventricle. (C) Anatomical continuity between the right ventricle and pulmonary artery was established by interposition of an external valved conduit. $T$, tricuspid valve, $S$, interventricular septum; $A$, aorta; $P$, pulmonary artery; $G$, Dacron patch graft used in the closure of the ventricular septal defect. 
great arteries easily creates the appearance of an abnormal connection. Classification is less difficult in cases with discordant ventriculo-arterial connection and anterior aorta, in which the outflow tracts do not cross. In case 5, the initial impression at operation was that the aorta was completely connected to the left ventricle (Fig. 7). However, the relation of the infundibulo-ventricular fold to the muscular interventricular septum (slightly to the right but not completely aligned) proved that a small part of the aorta was above the right ventricle, though more than two-thirds of the (tricuspid) aortic valve was above the left ventricle.

In the absence of atrioventricular discordance, the finding of an anterior descending coronary artery arising from the right coronary artery and leaving both great arteries to its left suggests DOLV. However, this coronary artery pattern is common in cases of anatomically corrected malposition (Otero Coto et al., 1978), in which the aorta is anterior and to the left of the pulmonary artery with ventriculo-arterial concordance, and can occur in other anomalies.

The designation DOLV is not incompatible with a univentricular heart, since the ventriculo-arterial relations and connections are determined by the same rules as in hearts with two well-developed ventricles (Otero Coto, 1977). However, we prefer the designation double outlet of chamber of left ventricular morphology when considering univentricular hearts. Since in univentricular hearts with double outlet left (main chamber) ventricle, neither great artery arises from the blind outlet chamber, we prefer to describe this as a 'trabeculated pouch' (Shinebourne et al., 1978).

DOLV (or chamber of left ventricular morphology) with intact septum or with a non-committed ventricular septal defect (thus far not described) might be classified as complete forms, while DOLV with one or both great arteries related to a ventricular septal defect could be considered incomplete or partial forms.

\section{SURGICAL IMPLICATIONS}

Correction of DOLV can be accomplished by intraventricular rerouting, provided that both ventricles are of adequate size, that there is no obstruction to the outflow tracts, or that obstruction if present can be surgically relieved, and that the ventricular septal defect is either subpulmonary or doubly-committed and non-restrictive. However, all of these conditions are seldom met and surgical correction must then be achieved by closing the ventricular septal defect, thus leaving both great arteries connected to the left ventricle, and by placing an external valved conduit between the right ventricle and the pulmonary artery.

Because of the high incidence of a coexisting hypoplastic right ventricle or of anomalous atrioventricular connections, many patients with double outlet of morphologically left ventricular chambers are unfortunately at present unsuitable for total correction. Some are candidates for palliative operations and a few may be suitable for a Fontan type of operation, as was done in the patient reported by Sharratt et al. (1976).

An accurate assessment of the size of the right ventricle and of the anatomy and function of the atrioventricular valves is indispensable in planning an operation, and other important considerations are the presence, size, and position of the ventricular septal defect and the degree and type of pulmonary and aortic outflow tract obstruction.

\section{EMBRYOPATHOGENESIS}

According to Goor et al. (1972), the definitive configuration and the type of connection of the outflow tracts of the ventricles results mainly from 3 developmental processes: conotruncal (bulbar) inversion, leftward shift of the conoventricular junction, and absorption of the conus. These processes are not necessarily linked to each other. DOLV would be the result of conotruncal leftward 'overshift' (Goor and Edwards, 1973), and the varied infundibular patterns the result of different degrees of conus absorption, while different degrees of conotruncal inversion (clockwise or counterclockwise) would explain the different relations of the great arteries. The frequent occurrence of hypoplastic right ventricle or univentricular heart in patients with double outlet of a left ventricular chamber suggests that those anomalies are pathogenetically related to DOLV (De la Cruz, 1977). Aortic laevoposition, which is in our experience frequently associated with right ventricular hypoplasia, is relatively more common in double outlet left ventricular chamber than in any other type of ventriculo-arterial connection with conccrdant atrioventricular connection (Otero Coto, 1977).

\section{References}

Anderson, R. H., Galbraith, R., Gibson, R., and Miller, G. (1974). Double outlet left ventricle. British Heart fournal, 36, 554-558.

Bargeron, L. M., jun, Elliot, L. P., Soto, B., Bream, P. R., and Curry, G. C. (1977). Axial cineangiography in congenital heart disease. Section I: Concept, technical and anatomic considerations. Circulation, 56, 1075-1083.

Brandt, P. W. T., Calder, A. L., Barratt-Boyes, B. G., and Neutze, J. M. (1976). Double outlet left ventricle. Morphology, cineangiocardiographic diagnosis and surgical treatment. American fournal of Cardiology, 38, 897-909.

De la Cruz, M. V. (1977). Double-cutlet and double-inlet ventricular complexes. In Second Henry Ford Hospital 
International Symposium on Cardiac Surgery, p. 214, ed Julio C. Davila. Appleton Century Crofts, New York.

Fragoyannis, S., and Kardalinos, A. (1962). Transposition of the great vessels, both arising from the left ventricle (juxtaposition of pulmonary artery). American fournal of Cardiology, 10, 601-604.

Goor, D. A., Dische, R., and Lillehei, C. W. (1972). The conotruncus: I. Its normal inversion and conus absorption. Circulation, 46, 375-384.

Goor, D. A., and Edwards, J. E. (1973). The spectrum of transposition of the great arteries: with specific reference to developmental anatomy of the conus. Circulation, 48, 406-415.

Kirklin, J. W. (1973). Introduction. In Advances in Cardiovascular Surgery, pp. 1-7, ed J. W. Kirklin. Grune and Stratton, New York.

Otero Coto, E. (1977). Levoposiciones aórticas sin inversión ventricular. Tesis Doctoral, Facultad de Medicina, Oviedo.

Otero Coto, E., and Quero Jimenez, M. (1977). Aproximación segmentaria al diagnóstico y clasificación de las cardiopatias congénitas. Fundamentos y utilidad. Revista Española de Cardiologia, 30, 557-566.

Otero Coto, E., Quero Jimenez, M., Cabrera, A., Deverall, P., and Caffarena, J. M. (1978). Aortic laevopositions without ventricular inversion. European fournal of Cardio$\log y, 8,523-541$.

Pacifico, A. D., Kirklin, J. W., Bargeron, L. M., jun, and Soto, B. (1973). Surgical treatment of double outlet left ventricle: report of 4 cases. Circulation, 47 and 48, Suppl. III, 19-23.

Paul, M. H., Muster, A. J., Sinha, S. N., Cole, R. B., and Van Praagh, R. (1970). Double outlet left ventricle with intact ventricular septum: clinical and autopsy diagnosis and developmental implications. Circulation, 41, 129-139.
Quero Jimenez, M., and Maitre Azcárate, M. J. (1975). Ventrículo izquierdo de doble salida: estudio de un caso y revisión de la literatura. Revista Española de Cardiologia, 28, 587-596.

Quero Jimenez, M., and Perez Martinez, V. (1974). Uncommon conal pathology in complete dextrotransposition of the great arteries with ventricular septal defect. Chest, 66, 411-417.

Rokitansky, K. F. (1852). A Manual of Pathological Anatomy, Vol. IV, p. 149. The Sydenham Society, London.

Sakakibara, S., Takao, A., Arai, T., Hashimoto, A., and Nogi, M. (1967). Both great vessels arising from the left ventricle. Bulletin of the Heart Institute fapan, 66-86.

Sharratt, G. P., Sbokos, C. G., Johnson, A. M., Anderson, R. H., and Monro, J. L. (1976). Surgical "correction" of solitus-concordant, double outlet left ventricle with l-malposition and tricuspid stenosis with hypoplastic right ventricle. Fournal of Thoracic and Cardiovascular Surgery, 71, 853-858.

Shinebourne, E. A., Anderson, R. H., Macartney, F., and Tynan, M. (1978). In Paediatric Cardiology 1977, ed Robert H. Anderson and Elliot A. Shinebourne. Churchill Livingstone, Edinburgh.

Van Praagh, R., and Weinberg, P. M. (1977). Double outlet left ventricle. In Heart Disease in Infants, Children and Adolescents, pp. 367-380, ed A. J. Moss, F. H. Adams, and G. C. Emmanouilides. Williams and Wilkins, Baltimore.

Requests for reprints to Dr Eduardo Otero Coto, Servicio de Cirugia Cardiovascular, Ciudad Sanitaria 'La Fe', Valencia 9, Spain. 